\title{
CORRESPONDENCE
}

\author{
Correspondents are asked to be brief \\ Treatment of Early Breast Cancer \\ W. P. Greening, F.R.C.S.; G. Y. \\ Feggetter, F.R.C.S. \\ Coccid:an-like Nature of Toxoplasma gondii \\ D. G. Fleck, M.D., and others............111 \\ Contaminated Drip Fluid \\ I. T. Stuttaf ord, M.R.C.S., M.P...........112 \\ Herpes Simplex and Temporal Lobe \\ Ep;lepsy \\ Constance A. C. Ross, M.D..............112 \\ Aetiology of Varicosity \\ A. A. R. Gossage, M.R.C.s. \\ Treating Incontinence Electrically \\ C. D. Collins, F.R.c.s., and Eileen \\ Montgomery; J. P. Williams, F.R.C.S., \\ and S. L. R. Stanton, F.R.C.S...........112 \\ Benign Breast Swelling \\ D. H. Patey, F.R.C.S. \\ Serological Reactions in Erythema Multiforme
}

N. R. Grist, F.R.C.P.ED., F.R.C.PATH......113
Skin Trauma and Corticosteroids

Joan Sneddon, Cortico

Child Abuse Syndrome

W. H. Parry, M.D., and Margaret W.

Seymour, D.P.H.; S. M. Smith, D.P.M...113

Rickets in Glasgow Pakistanis

J. M. Round, B.sc.

Febrile Convulsions in Early Childhood

J. Wilson, F.R.C.P.....................114

Carcinoma of Tongue

R. A. Cawson, M.D.

Fenfluramine and Pigmented Naevi

D. W. Bartlett, M.R.C.S.

Quantitation of Transplacental

Pharmaceutical Literature

A. G. Shaw, F.P.S

Age and Anorectal Dilatation

Katharine M. Fussell, F.R.C.S.

Slimming and Efficiency

P. T. Monard, M.SC., M.B............115
Unwanted Pregnancies

Kathleen M. Huntington, M.B..........115

Infection in Rheumatoid Disease

H. C. Burry, M.R.C.P..........

C. M. Fletcher, F.R.C.P.................116

Plantar Warts

D. C. Shields, M.B.; W. G. R. M. Laurie,

M.B.; S. S. Sanders, M.B................116

Stress and the Schizophrenias

W. L. Neustatter, F.R.C.P. 116

Change of Address

M. R. Draper, B.A.

New Consultant Contract

A. I. Mackenzie, F.F.A. R.C.S...........117

Rate for the Specialty

J. A. C. Neely, F.R.C.s...............117

Hands off Postgraduate Centres

G. C. Davy, M.A., F.H.A.....

Primary and Community Care

P. E. Brown, M.R.C.P.

\section{Treatment of Early Breast Cancer}

SIR,-It would be a pity if criticism of technical detail were allowed to detract from the enormous contribution which the Guy's trial (20 May, p. 423) has made to the current discussion about the management of women with operable breast cancer.

It is the first prospective trial which has confirmed what others have concluaied from clinical experience-namely, that the breas can be conserved safely when the axillary lymph nodes are not involved and, probably, when the tumour is small and not multifocal

In the management of breast cancer it is essential to know if the axillary lymph nodes are invaded. One conclusion that might be drawn is that at the time of the tylectomy the nodes in the lower axilla below pectoralis minor (level 1) should be removed. If on frozen section examination they are invaded, the axillary dissection should be completed in conjunction with a total mastectomy. If the nodes are histologically clear, further treatment could be limited to irradiation of the breast and perhaps the parasternal nodes.

This approach would retain the uninvolved nodes in levels II and III of the axilla. The W.H.O. Breast Group is trying to include this kind of approach into a future trial.-I am, etc.,

W. P. GREENING

The Breast Unit

Royal Marsden Hospital,
London S.W.3

SIR,-I am very interested in the "Report after Ten Years of a Clinical Trial" (20 May, p. 423) and agree that results in stage 2 patients treated by local excision and radiotherapy were so inferior to radical excision and radiotherapy that for them this procedure should be abandoned, but I wonder whether it is not a mistake to continue with it in stage 1 patients.
Though the information is incomplete (actual yearly figures, cause of death, time of appearance of metastases, etc.) it is possible to reach such a conclusion by studying the graphs and the statistics supplied. There were 220 stage 1 patients admitted to the trial in ten years, an average intake of 22 per year, half being treated by local excision with radiotherapy and half by radical excision and radiotherapy, but only 110 of these have been in it for more than five years, the remainder being too few in each additional year for analysis.

By the end of five years after operation $20 \%$ were dead (Fig. 2), leaving 88 survivors, half having had one form of treatment and half the other. Distant dissemination was equal in both groups, but local recurrence was much higher in those treated by local excision and radiotherapy. Thus the incidence of local recurrence was (Fig 3): (a) Local excision and radiotherapy $20 \%$ of 44 patients =9; (b) Radical excision and radiotherapy $4 \%$ of 44 patients $=2$.

Within 10 years of the beginning of the experiment local cancer recurrence rate was (Tables III and IV): (a) Local excision and radiotherapy -15 patients; (b) Radical ex cision and radiotherapy -4 patients.

Twelve of the 15 patients with local recurrence after local excision and radiotherapy were treated (Table $\mathrm{V}$ ) and of these, six developed distant metastases and six were reported as free from cancer, no postoperative period being given, but in my experience of a carefully studied personal series of 150 patients with carcinoma of the breast operated on more than 10 years previously (some followed for 25 years) not a single patient who developed local recurrence was found to be free from cancer 10 years after it appeared-in spite of all methods of treatment.

Looked at in this way I suggest that the trial in stage 1 patients be terminated as well as in stage 2 , but of course the continued progress of the survivors should be noted and reported.-I am, etc.

Jesmond,
Newcastle upon Tyne 2

George Y. FegGetTer

\section{Coccidian-like Nature of Toxoplasma gondii}

SIR,-Dr. W. M. Hutchison and others (17 January 1970 , p. 142) showed the coccidianlike nature of Toxoplasma gondii and the sexual part of the cycle in the domestic cat. Although the oocyst has been found in the faeces of domestic cats in surveys in other countries the evidence of transfer from cat to human has always been obscure. Since Dr. Hutchison published his work this laboratory has tried to investigate acquisition of the infection in cases with high or rising toxoplasma dye test titres. Thus the following case may be of interest.

A 40-year-old married woman with two children, a boy aged 5 years and a girl aged 7 years, became ill in Ocrober 1971 with lymphadenopathy. The mother's dye test titre rose from $1 / 512$ to $1 / 4,000$, with the toxoplasma IgM titre 1/16. Her boy, however, had a titre of $1 / 8,000$ in January 1972 but no rising titre could be demonstrated. On investigation it was found that the family owned a dog but no cat. Soil samples and samples from a sand pit in the garden were suspended in $2.5 \%$ sodium dichromate. The coarse sediment was discarded and the supernatant concentrated using ether. The resultant concentrate was washed and injected into mice known to be free from toxoplasma infection. After six weeks the mice injected with washings from the sand developed toxoplasma antibody showing that infective material had come from the sand At the time of collection the sand samples were moist and frequently used by the cat 
next door, whose serum was found to be positive in the dye test at a titre of $1 / 256$.

Although further work is needed to substantiate this link in human infections, it indicates that epidemiological work along these lines may well be rewarding.

We wish to thank Drs. J. B. Sayer and D. J. McBrien for help with this investigation. Serum from the cat was sent to us by Mr. J. C. Wooton, M.R.C.V.S.

-We are, etc.,

D. G. FleCK

B. S. CHESSUM

M. Perkins

Public Health Laboratory,

St. George's Hospital,

\section{Contaminated Drip Fluid}

SIR,-Recent events involving intravenous fluids have prompted considerable comment in the scientific and popular press, with specific criticisms of autoclaves, solution containers, and quality control procedures. ${ }^{12}$ However, any improvement in manufacturing techniques, although welcome, must be accompanied by investigations on a much wider front into the whole practice of intravenous therapy, and this is the point which I was trying to make in my recent Questions to Sir Keith Joseph when he was making his statements in the House of Commons (see 18 March, p. 759). The responsibility that intravenous therapy remains a safe and effective technique rests with all the professional groups involved-the medical staff, the nursing service, and the pharmacist.

It is impractical to expect the doctor who prescribes treatment fully to appreciate the chemical pharmacology and incompatibilities of all drugs. Literature on the stability of drugs and the addition of supplementary medication to blood or infusion fluids is often contradictory. Tetracycline alone is incompatible with over 50 other common chemicals, and antihistamines are routinely added to blood packs. The recommended frequency of changing an administration set or cannula varies from "with every bottle"3 to "after 48 hours," and the medical student receives little instruction on these points. In a recent case in a teaching hospital which came to my notice 13 different bottles were administered through the same giving set. Not surprisingly, this had become infected and there was an adverse, luckily mild, reaction.

Nursing staff, who invariably perform the last quality check, are increasingly expected to make complicated pharmaceutical calculations and reconstitute drugs for mixing with intravenous fluids on non-sterile wards, again without formal training or education. The pharmacist, for too long merely a dispenser, has the appropriate training and qualifications to provide all information and advice on drug interactions, aseptic technique, and bioavailability. He must, therefore, be encouraged to extend his responsibilities outside the pharmacy, provide a 24-hour service, and become an active member of the health team, the rest of whom, in their turn, must be encouraged to respect his advice.

Now that over $17,500,000$ units of intravenous fluid are given to patients annually, the time is opportune to re-examine the habits which for too long have been allowed to evolve in a haphazard manner. With support from the teaching hospitals, N.H.S administrators, and the medical and nursing professional bodies the responsibilities and rules for trouble-free intravenous administration technique must be clearly defined. A circular from the Department of Health and guidance from the defence societies would help to achieve this end.-I am, etc.,

House of Commons,

TOM STUTTAFORD

London S.W.1

1 Perera, R., Pharmaceutical fournal, 1972, 208, 469. 2 Sterne, M., New Scientist, 1972, 54, 272. Mollison., New Slientist, Transusion, in Clinical Medicine. 4th edn., 614. Oxford, Blackwell, 1967.

4 Dunbar, J. M., Modern Medicine, 1972, 17, 142.

\section{Herpes Simplex and Temporal Lobe Epilepsy}

SIR,-The discussion on the causes of temporal lobe epilepsy in the interesting paper by Mr. Murray A. Falconer (10 June, p. 631) revealed that herpes simplex infection had probably not ben considered as a possible cause of this condition.

Many recent studies have now shown that herpes simplex infection is apparently the commonest cause of severe acute encephalitis in older children and adults, the usual histological picture being an acute necrotizing encephalitis. ${ }^{1}$ It appears that this acute presentation is uncommon in young children. Thus, in our own laboratory during the 10-year period 1962-71, a firm diagnosis of herpes encephalitis was made in 20 patients in the west of Scotland on the basis of histological evidence of encephalitis along with isolation of virus from brain and/or serological findings indicative of current herpes simplex infection. Only one of these 20 was under 10 years old, and his illness differed from the others in having subacute onset at the age of 3 years followed by slow deterioration and death when 6 years old. In contrast, all the older children and adults had an acute severe illness; 12 of these 19 died, all in the acute phase of illness.

The possible importance of herpes simplex infection as a cause of severe convulsions in infancy later leading to temporal lobe epilepsy does not appear to have been adequately ascertained, because brain biopsy would of course not be carried out on such infants. However, a rising serum antibody titre for herpes simplex in such infants would give a firm indication of a current infection. I urge that paired sera for this investigation should be collected from all infants with severe convulsions so that the possible role of herpes simplex infection as an aetiological factor in temporal lobe epilepsy may be determined. Since antibody responses in infants are frequently slow the interval between the sera should be three to six weeks.-I am, etc.

Constance A. C. Ross Regional Virus Laboratory,

Ruchill Hospital

Glasgow

1 Adams, J. H., and Miller, J. D., Postgraduate

\section{Aetiology of Varicosity}

SIR,-I was impressed with Mr. D. P. Burkitt's paper (3 June, p. 556) on the relationship of Western society's low residue diet and varicose veins, haemorrhoids, and deep vein thrombosis.
I would like to give emphasis to a different aspect of this problem. A major factor limiting appetite is gastric distension, which the refined Western diet does not achieve until a large number of calories have been ingested. With lack of deliberate self control, obesity is now causing a progressive decline in health in economically developed communities. This obesity does not develop without inactivity, and the proportion of people in Westernized society in sedentary occupations is very different from that in African society.

This inactivity allows venous pooling and distension in the legs causing incompetency of the valves, which is then considerably aggravated by straining at stool. Venous flow in the legs is against considerable gravity, and the bumping assistance of the muscles is needed to maintain a satisfactory rate of flow. Sluggish bowel movement and constipation occur in the generally inactive so that the sedentary person will do more straining at stool.

The postulation of the weight of the colon as the main cause of deep vein thrombosis is difficult to accept. The African bowel has a heavier content, larger volume, and is a bigger structure altogether, as shown by its tendency to volvulus. Thus there will be more compression of the deep veins in the African than by a low residue containing colon. Obesity and inactivity are as improtant aetiological factors as straining at stool. The chances of an individual developing deep vein thrombosis depend directly on his fitness and the condition of his veins before operation. The lean, fit African is at considerably less risk than the obese, unfit European.-I am, etc.,

A. A. R. Gossage

Westminster Hospital,

Westminster
London S.W.1

\section{Treating Incontinence Electrically}

SIR,-Your leading article "Treating Incontinence Electrically" (17 June, p. 670) presented a fair review of one of the methods of electrical treatment at present available but, by failing even to mention other techniques, highlighted the dismaying gulf that is apparent between those who have recently started using new electronic gadgets and those who have been treating incontinence electrically for over a century-namely, the physiotherapists.

If continuous electrical stimulation is to have any permanent place in the therapy of incontinence, it must be shown either to have an objective effect on the sphincter mechanisms justifying its use, which it does not, ${ }^{12}$ or to be effective in controlling types of incontinence for which no simpler method of treatment is available. Neither of these criteria is satisfied in respect of treatment of stress incontinence. Jones and $\mathrm{Kegal}^{3}$ reported a $43 \%$ cure rate by exercise alone, Tanner ${ }^{4}$ reports a $55 \%$ success using faradic stimulation as an adjunct to physiotherapy, and Moore and Schofield ${ }^{5}$ report $33 \%$ success in patients reviewed one year after 30 seconds treatment with powerful faradic stimulation under anaesthesia. We found a $50 \%$ cure rate in selected cases using a method of powerful faradic stimulation under anaesthesia followed by physiotherapeutic instruction augmented by the use of intermittent stimulation when neces- 